\title{
Addressing the Issues of Maintenance Management in SMEs: Towards Sustainable and Lean Maintenance Approach
}

\author{
Adnan Bakri ${ }^{1 *}$, M.F.M. Alkbir ${ }^{1}$, Nuha Awang ${ }^{1}$ Fatihhi Januddi ${ }^{1}$, M.A. Ismail ${ }^{1}$, \\ Ahmad Nur Aizat Ahmad ${ }^{2}$, Izatul Husna Zakaria ${ }^{3}$ \\ ${ }^{1}$ Advanced Facilities Engineering Technology Research Cluster, Universiti Kuala Lumpur Cawangan Malaysian Institute of Industrial \\ Technology, 81750 Masai, Johor, Malaysia \\ ${ }^{2}$ Department of Production and Operation Management,Faculty of Technology Management and Business, Universiti Tun Hussein Onn, \\ Malaysia 86400 Parit Raja, Batu Pahat,Johor, Malaysia \\ ${ }^{3}$ School of Technology and Logistics Management, Universiti Utara Malaysia, 06010 UUM Sintok, Kedah, Malysia
}

\begin{abstract}
This paper outlines on the preliminary outcomes of pilot project aimed at exploring the issue related to managing of maintenance activity in the Malaysian Small and Medium Enterprises (SMEs). SMEs have been accepted as vital components of domestic industry development in many countries. However, the literature portrays that many of Malaysian SMEs particularly the companies involved in manufacturing, fabrication and machining services are struggling to manage the maintenance of their manufacturing equipment. Dependable manufacturing equipment is important factor towards organizational profitability. Managing the maintenance activity of those manufacturing equipment nowadays, is becoming more challenging due to automation and computerization. Due to such issues, SMEs companies are under stiff pressure to minimize lost time for their survival. Thus, this study seeks to explore the related issues towards further improvements. Qualitative research methodology was adopted in the study. Data were collected at eight (8) SMEs located in three (3) different areas, namely southern, central and eastern region of peninsular Malaysia. Information was gathered from semi-structured interviews with SMEs management and observations focuses on different areas of maintenance management at the respective SMEs. The main concern is to validate the critical success factors (CSFs) in managing the maintenance activity at selected SMEs. This study discovered that nine (9) CSFs are having the most significant impact towards improving the maintenance management practice for SMEs. These include: understanding the MM philosophy; management commitment and leadership; maintenance strategy; maintenance planning; maintenance training; monitoring and assessment; appropriate number of maintenance staff; integration of tools, techniques and technology, and; record of maintenance data. All those CSFs construct are integrated in a simple yet selfexplanatory MM Framework to convey the conceptual idea of MM implementation program to the management and technical people within SMEs. It is believed that the MM Framework developed would serve as an indicator of company's MM focus level. Through the identification of the CSFs constructs, the SMEs can utilize the information to improve their approach in systematic MM program. The discovered CSFs are vital for all stakeholders that directly or indirectly involve in managing the maintenance activity in SMEs.
\end{abstract}

\section{Keywords:}

Maintenance Management;

SMEs;

Critical Success Factors

Case Study.

\section{Article History:}

$\begin{array}{llll}\text { Received: } & 02 & \text { February } & 2021 \\ \text { Revised: } & 29 & \text { April } & 2021 \\ \text { Accepted: } & 12 & \text { May } & 2021 \\ \text { Published: } & 01 & \text { June } & 2021\end{array}$

\section{1- Introduction}

There is consensus among many authors that quality improvement (QI) initiatives are influenced by equipment reliability and maintainability $[1,2]$. The wastes generated during production processes is directly proportionated with the performance of production equipment. The malfunction and failure of equipment would result in poor quality product

*CONTACT: Adnanb@unikl.edu.my

DOI: http://dx.doi.org/10.28991/esj-2021-01283

(C) 2021 by the authors. Licensee ESJ, Italy. This is an open access article under the terms and conditions of the Creative Commons Attribution (CC-BY) license (https://creativecommons.org/licenses/by/4.0/). 
and as consequence delayed delivery [3]. Satisfying customers' requirement in timely manner means the equipment availability is required to be at its peak level. Through a systematic and strategic maintenance management (MM), defects and variations resulting from the poor equipment could be eliminated [4, 5]. Hence, equipment efficiency should include product quality index as well rather than focusing on the equipment availability alone [6]. However, it is observed that the significant role of MM as an important constituent of QI initiatives is not emphasized in the literature, particularly in Small and Medium-sized Enterprises (SMEs) [6-8]. This paper aimed at two main objectives. First, it provides a brief review on the actual practice of MM in Malaysian SMEs. The main concern is to identify the critical success factors (CSFs) in managing the maintenance activity in SMEs. Second, a framework for lean maintenance approach is presented. The design of the framework is intended to help SMEs in handling the issues related to MM.

\section{2- Literature Review}

\section{2-1- Overview of Quality Improvement Initiatives}

In today's highly competitive economic environment, quality emerges as an effective strategy for the manufacturing companies towards the success, growth, and enhances their competitive position. Hence, in order to survive, every manufacturing company has to infuse the quality improvement (QI) initiatives such as total quality management (TQM), lean manufacturing and just-in-time (JIT) in all aspects of their operations [9-11]. The emergence of these progressive QI initiatives has changed tremendously the nature of manufacturing environment. They are utilized with the aim at positioning ahead of competition in term of production efficiency, excellent product quality, satisfies the customers' deadline and optimizing the operational cost. Under TQM philosophy, the quality control and assurance of product is moved to the production process instead of inspection at the final product. The defect and variation of product are eliminated at the production processes through adequate process control techniques $[12,13]$. Lean manufacturing is a philosophy and a way of working aims at reducing the operating costs through the elimination of waste in the production processes. "Waste" is defined as anything that does not add value in the production process. Lean manufacturing focuses on the elimination of waste in all forms, these include: defects; rework; unnecessary processing steps; unnecessary movement of materials or people; waiting time; excess inventory, and; overproduction [14]. On the other hand, JIT is one the key element in lean manufacturing. It emerges as a technique for inventory management. The principle that underpins JIT is that production should be 'pulled through' rather than 'pushed through'. This means that product is produced based on specific orders from customer. The production starts only once a customer has placed an order with the manufacturer. JIT however is not a mere inventory control technique, but a manufacturing system that try to enhance quality and lower costs through the reduction of inventories and shortening lead times [15-17].

\section{2-2- Negligence of Maintenance Management in QI Initiatives}

Reliable equipment is considered as the main elements towards performance as well as profitability of the organization. Therefore, it is vital that those QI initiatives to be integrated with maintenance. However, a review on the literature of the recent work (articles published from 2018-2021) portrays an evidences of some criticalities in maintenance management in manufacturing industries particularly in small firms, such as too much "fire-fighting" i.e. still applying the concept of breakdown maintenance and limited preventive approaches [18, 19]. The negligence in maintenance management will have significant impact on company's profitability. A huge amount on maintenance of inefficient production equipment would increase up the company operational costs. Effective MM of production equipment and its integration with QI initiatives is one of the vital requirements towards achieving the world-class manufacturing [20]. Therefore, it has been established beyond any doubt, such integration of MM and QI initiatives plays an important role to spur the company's economy, particularly as part of essential strategies to face the stern competitiveness and cope up with increasing pressure of market globalization [21]. However, the integration of MM and QI initiatives requires a further study aimed at improving its effectiveness and determining the critical gap related to limitations and constraints in real implementation.

\section{2-3- Contribution of Malaysia's SMEs}

Small and medium enterprises (SMEs) are vital for the economic growth in most of the countries [22]. In Malaysia, SMEs have a great role towards increasing the country's gross domestic product (GDP. Currently, SMEs in Malaysia contribute about 37\% to the country's GDP [23]. In manufacturing sector, SMEs play an important role as a supplier for an original equipment manufacturer (OEM) of components and parts to larger organizations. Hence, substandard product quality supplied by the SMEs could affect to the finished product of the larger organizations. SMEs encounter significantly different business landscapes and challenges relative to bigger organizations. SMEs are under enormous pressure to sustain their business survival due to aggressive global competition particularly related to technological advancement and changing needs of customers. Of significance, SMEs necessitates some inventive techniques to elevate the maintenance of their manufacturing equipment towards a superior, competitive and reliable product quality. The issues of SMEs and its significant impact on the global supply chain has captivated many researchers to contribute the idea and explore potential opportunity for the further improvement in the MM and QI initiatives. This study will attempt to synthesize a various issues related with CSFs for managing the maintenance activity in SMEs towards providing a comprehensive conceptual framework as a guide for MM in SMEs. 


\section{2-5- Critical Success Factors for Maintenance Management in SMEs}

In order to succeed in the implementation of MM system, the SMEs need to be attentive about each elements of critical success factors (CSFs) for MM. Based on the analysis of the previous studies of MM, nine CSFs constructs having the most substantial impact in MM implementation were summarized using the affinity diagram technique [24]. This technique comprises of three steps, namely: Step 1: Extracting the key points of CSFs from literature sources (journals, books, etc.); Step 2: Consolidating of all CSFs key points in database, and; Step 3: Clustering and filtering the CSFs key point to a final CSFs main constructs. Figure 1 summarizes the main CSFs constructs derived from previous studies, which is designated as MM Framework I. The base for the development of MM Framework I replicated the works by previous researchers. Those nine CSFs constructs were combined based on the cause-and-effect diagram as developed by Ishikawa [25].

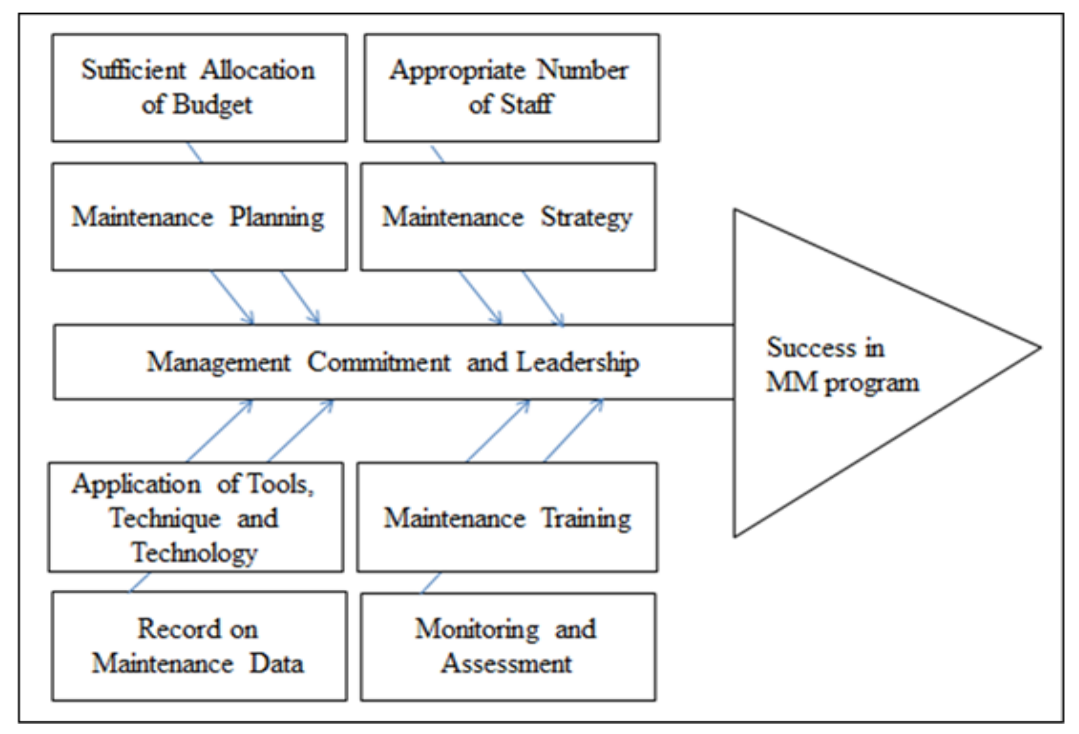

Figure 1. MM Framework I - adapted from: [26, 27]

The basis of the MM Framework I indicates the significant role of top management in managing the issues related to human and operational contextual factors in MM program. A journey towards improving the MM necessitates a drastic change in the mind-set and working culture of all employees. Those tasks are very challenging and it is a crucial factor which must be carefully addressed by the top management before initiating the MM program. The top management ought to have a domineering role in defining the maintenance policies, approaches, provision of resources and bring into line with the company's business goals. The focus on training and education would inculcate employee to change the mind-set and keen to take possession for the care of their equipment. Training and education is one of the significant determinants to ensure the success in MM. Sufficient and effective training programs would improve competency of employee on MM techniques. The focus on the operational contextual factors would be the subsequent part after the human contextual factors have been addressed. Bakri et al. [28] highlighted that to ensure the success of MM, the approach should be realistic with strategic planning and structured implementation approach. The integration of MM program with relevant tools, techniques and technology will ensure the MM initiative sustains. The application of computerized system would assist the company in scrutinizing the maintenance data for equipment. Appropriate monitoring of performance and evaluation on the progress of MM would enable management to review on the achievements and further improve any hiccups in the implementation.

\section{CSF 1: Management Commitment and Leadership}

The key parameter of the framework illustrates the vital role of top management in overseeing the unabridged activities in MM program. It is obligatory for the top management to ensure the paradigm shift in the working culture. The top management should really active and participate in the MM implementation process rather than just wait for the results. A set of firm strategies should be established to easy the overseeing process, for example: establishment of explicit MM policy and objectives; provision of resources, and; appointment a champion to lead the program [29].

\section{CSF 2: Sufficient Allocation of Budget}

The top management must provide an appropriate financial funding to support the program. A major financial funding is required to support the MM process, particularly in providing sufficient maintenance staff, materials, tools and training resources are under the responsibility of top management [30]. 


\section{CSF 3: Appropriate Number of Staff}

Having adequate maintenance staff on hand is an important component in the success of SMEs. The shortages of maintenance staff can result in production shortfalls and inability to meet the needs of customers. Employee turnover is expensive. Apparently, it is important for the company to reduce turnover rates. However, in order to reduce these rates, the company must first understand the main reasons employees leave for other companies [31].

\section{CSF 4: Maintenance Planning}

Strategic maintenance planning is vital for the success of MM program. The company intended to implement a systematic MM program should have a comprehensive strategic planning with an explicit clarification of company direction on MM and how it is going to attain those goals by various activities such as : identification of the internal strengths and weaknesses as well as external opportunities and threats (SWOT); developing necessary action plan; allocating a sufficient resources; arranging the tasks to pursue goals; nurturing communication and teamwork; assessing the progress; making essential rectifications to the company's direction in response to the results [32]. Without a deliberate planning on MM implementation plan, the program will not succeed.

\section{CSF 5: Maintenance Strategy}

Suitable and effective maintenance strategy will lead to improve machine reliability and availability. A thorough understanding on the fundamental knowledge of maintenance standard and approach will help company to draft an effective maintenance strategy. Maintenance strategy in general includes two main approaches, which is corrective and preventive maintenance. The latter is then expanded to other new approach as such Reliability Centered Maintenance (RCM), Conditioned Based Maintenance (CBM) and Total Productive Maintenance (TPM). Acceptable maintenance technique depends very much on available maintenance resources with consideration of common factors such as characteristics related to management factors, complexity of equipment, technical knowledge, and financial allocation $[33,34]$. One of the highly recommended strategies is to adapt the Autonomous Maintenance (AM) techniques. AM technique focus to inculcate the production operators to participate in doing the minor maintenance activities such as periodical cleaning, lubricating, tightening and minor replacement (CLTM) of equipment parts [35].

\section{CSF 6: Integration of MM with Relevant Tools, Techniques and Technology}

Technology becomes a tool for assisting maintenance personnel to improve the maintenance operation efficiency. The integration of MM program with relevant tools, techniques and technology will guarantee the success. For instance, the application of analysis techniques in 7-QC tools, Why-why and Fault Tree analysis would enhance the root cause analysis for maintenance problem. On the hand, the use of Computerized Maintenance Management System (CMMS) software would ease the company in analyzing the maintenance data for equipment. The proper use of CMMS software would provide an accurate data for equipment and machine performance [36, 37].

\section{CSF 7: Maintenance Training}

Training and education (TE) is one the vital element in any quality improvement initiatives, not restricted to MM implementation program. A well-crafted TE module should be given to each employee in the organization (it must be based on their dedicated role and tasks). Generally, the there are two type of TE available, i.e.: general and technical training. Technical TE focuses towards providing technical staff with necessary knowledge, skills and techniques in maintaining the equipment [38]. The company also must focus on enhancing the operators' skills to detect the sign of deterioration on production equipment. All employees in the organization should be considered as invaluable human assets, therefore the TE activities for them is deemed necessary. TE activities should be started as earlier as equipment in the commissioning stage. The equipment's designer and manufacturer should be involved from earlier stage in order to systematically support the matter related to TE of equipment. Emphasizes on TE for all relevant employee would prolong the equipment lifespan [39].

\section{CSF 8: Record on Maintenance Data}

A reliable method to monitor and assess the overall equipment effectiveness (OEE) of the equipment should be established. This is to avoid pitfall in judging the actual performance of MM implementation program. The concept of equipment availability, equipment performance rate and quality rates of the product produced should be well understood by the employee of the organization [40].

\section{CSF 9: Monitoring and Assessment}

Steering committee consists of all relevant departmental managers should be established to ease coordinating and assessing the progress of MM implementation program. A proper monitoring and assessment methods would ensure the 
implementation program follow the correct track. An instantaneous analysis on the root causes need be carried out if the outcomes are not satisfying with the expectation [41, 42]. The management team need to be proactive by establishing a systematic monitoring and evaluation approach to ensure success in the implementation MM program.

\section{3- Methodology}

The research was designed to gather the views and opinions towards identifying the key barriers and drivers for an effective maintenance management in Malaysian SMEs. For this purpose, case study methodology is used in order to provide an insight and understanding on the actual practice of MM in Malaysian SMEs. Yin [43] recommended that a case study methodology is appropriate when trying to answer not only the "how" but also the "what", and "why" questions of research. Previous researchers have used the case study methodology to uncover and explore a wide range of issues in many field. Conducting multiple case studies can be described as being equivalent to replicating experience, and hence the outcomes are often considered more convincing. Prior of conducting the case studies, a research framework (designated as MM-Framework I) was designed as a research tool to validate the actual practice on how the SMEs managing the maintenance activities.

Based on the analysis of the previous studies of MM, nine CSFs constructs having the most substantial impact in MM implementation were summarized using the affinity diagram technique [6, 26]. This technique comprises of three steps, namely: Step 1: Extracting the key points of CSFs from literature sources (journals, books, etc.); Step 2: Consolidating of all CSFs key points in database, and; Step 3: Clustering and filtering the CSFs key point to a final CSFs main constructs. The case studies were conducted at eight (8) SMEs located in three (3) different areas, namely southern, central and eastern region of peninsular Malaysia, their details are given in Table 1.

For reasons of confidentiality, the companies are referred to as A-H. Information was gathered from semi-structured interviews with key peoples and observations focuses on different areas of maintenance management at the respective SMEs. Interviews of targeted key people responsible for maintenance management would be conducted each lasting for about three hours to enable a more in-depth investigation and provide a deeper understanding of the phenomena being studied. As for normal observation, a series of site visit were conducted during the case study. Walking around the site has given the opportunity to observe what the company practices. The site visits allow for greater understanding of how the company practices MM and the actual MM environment looks like is valuable evidence. The questions in the interview are open-ended type and the interviewees have been asked to share their experience and opinions on how maintenance management should be practice effectively in the company. Following the interviews, the transcripts were returned to the interviewees to check the accuracy of the recorded information. The data was analyzed using content analysis and cross-case approach. Cross-case analysis was utilized for analysis of qualitative data.

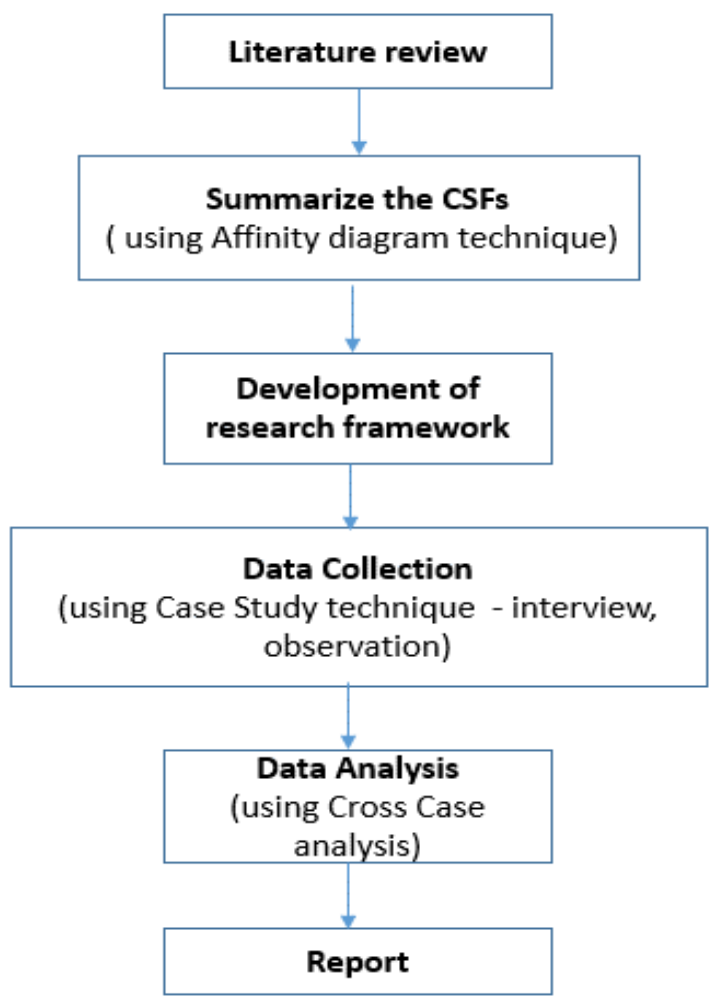

Figure 2. Flow for the activities in this study. 
Table 1. List of case study companies and respondents.

\begin{tabular}{ccc}
\hline Companies & Product / Location & Interviewees Position \\
\hline A & Frozen food / Johor & Manager \\
B & Herbal product / Melaka & Superintendent \\
C & Confectionery/ Melaka & Senior Engineer \\
D & Automotive parts / Selangor & Manager \\
E & Automotive parts / Selangor & Manager \\
F & Oil and gas component / Selangor & Superintendent \\
G & Steel fabrication / Terengganu & Manager \\
H & Automotive parts / Terengganu & Senior Manager \\
\hline
\end{tabular}

\section{4- Results: Case Studies Findings}

The eight case studies involved in this research aimed at exploring the issue related to managing the maintenance activity in Malaysian SMEs. MM Framework I (Figure 1) was used as research framework to assess on the actual MM practices in SMEs.

\section{4-1- Management Commitment and Leadership}

In order to ensure the success of MM program, the company should emphasise on the integration of MM program with company's policy. However, the finding from the case studies revealed that $62.5 \%$ companies did not have a specific policy about maintenance as part of important constituent in the management of the company (Case A, B, C, F and G). The available policy was only on general employment and business policy. Obviously, this indicated the poor commitment of the company's management on MM program [44]. However, it was not a case for company D, E and H. These companies are vendor to largest passenger vehicle producer in Malaysia (Company X). Company X has directed its vendors to implement the Total Productive Maintenance (TPM) activity in any of the workstation that produces Company X's items. Thus, indirectly the policy about maintenance as part of important constituent of management was available at companies $\mathrm{D}, \mathrm{E}$ and $\mathrm{H}$.

\section{4-2- Sufficient Allocation of Budget}

Most of the companies in the case studies have encountered a financial constraint in maintaining the production facility and equipment (Case A - case $\mathrm{H}$ ). Production facility and equipment may be old from the standpoint that it was purchased many years ago. Respondents from Case A and Case B mentioned that they are having financial constraint to continually upgrade and maintain the production facility in order to keep up with evolving manufacturing and production requirements

\section{Respondent Case A:}

"Due to cash flow constraints, buying machinery absolute is not a viable option for the company. We are having no choices, have to maintain the old and unreliable quality machineries".

\section{Respondent Case B:}

"Purchasing new machinery is a large financial decision that should have a strong justification. Some machinery costs a million of ringgit, so that purchase can dramatically alter the financial situation of overall company cash flow".

Those findings from the case studies contrasted with literature that pointed out the necessity of allocating the appropriate financial resources to maintenance department $[45,46]$.

\section{4-3- Appropriate Number of Staff}

Due to cutbacks in the yearly financial allocation by the management, maintenance department also was forced to rationalize their expenditure particularly in term of employee wages, welfare and compensation (Case B, C, F and G). Staff salaries are one of the critical expenses and those companies are now thinking at reducing the salary of maintenance staff. The other alternative for the companies is by hiring a lower qualification maintenance staff. Due to uncompetitive pay practices, those companies were having a high staff turnover rate. As a result, the maintenance departments of companies B, C, F and G are short-staffed. These issues are the same as faced by any maintenance management department, in which they cannot operate effectively with a short-staffed situation [47].

\section{Respondent Case C:}

"Years ago, many of us had the advantage of having good pay with opportunities to do extra overtime works definitely with extra pay and income, but nowadays, we are no longer enjoy it The management has implemented a massive cost saving activities and we are no longer allow to do extra overtime unless on special case". 


\section{Respondent Case G:}

"Our company experiencing not just a lack of maintenance staff, it is a lack of skilled staff as well. The highly trained, highly capable technicians have been moving out away from company and there is not many new staff to replace them".

\section{4-4- Maintenance Planning}

All of the interviewees (Case A - case $\mathrm{H}$ ) indicated that they have master plan for preventive maintenance (PM). The majority of these maintenance plans, however was not firmed and quite often it was ignored (Case A, B, C, F and G). The low priority given to maintenance and production output is the most widely favored. The maintenance priority was made on the basis of process bottle necks. Those practices can be regarded as ignorance in maintenance planning. This finding aligned with the issues highlighted in the literature that the ignorance on maintenance planning could be one of the causes of SMEs unable to manage the maintenance of the production facility and equipment [48, 49]. However, another cases (Case D, E and H), the companies had decided to follow strictly the PM schedule.

\section{Respondent Case A:}

"We realize the important of preventive maintenance, for every hour that a piece of machineries is down, our company loses revenue. With limited resources, we will try our best to follow the fixed preventive maintenance schedule".

\section{Respondent Case B:}

"Why we have to skip the fixed PM schedule? It was because the maintenance team are typically busy "putting out fires", which pushes anything "preventative" to the side".

\section{Respondent Case H:}

"Repair cost of broken machine is always more expensive than it is to maintain. Then it is better for us to really follow the PM schedule".

\section{4-5- Maintenance Strategy}

Further interview to determine the type of maintenance strategy applied shows that $50 \%$ of the cases $(\mathrm{Case} \mathrm{B}, \mathrm{C}, \mathrm{F}$ and $\mathrm{G}$ ) were still practicing the conventional way of doing maintenance on machineries. Interviewees from Case $\mathrm{B}$ and $F$ agreed that their companies operate according to the

"Fire-fighting" strategy in which maintenance works will be carried out once failure occurs. Most of the interviewees in Case B, C, F and G admitted that they did not really know about other systematic maintenance strategy for e.g. TPM as practiced in other companies (Case D, E and H). Further question to determine the level of integration of maintenance practices through the participation of production operators, shows that there was lack of involvement from operators in taking care of production machine. Operators were directed to concentrate to meet the production output only. According to respondent Case C, his company attempted to implement TPM twice during the early 2000s. However, both attempts were abandoned due to few reasons: change of top management; insufficient training on TPM techniques, and; poor involvement of employees. On the other hand, in other cases (Case D, E and H) researcher has attained other view on maintenance practice. Since companies D, E and H are implementing TPM, researcher has the opportunity to observe how the Autonomous Maintenance (AM) activities such as periodical cleaning, lubricating, tightening and minor replacement (CLTM) of machine parts by production operators were done. The practice of CLTM in daily AM activities seems commensurate with the practice of AM suggested by Nakajima [50].

\section{Respondent Case D:}

"AM activity really benefits our company, the CLTM activities allow production operators to assist maintenance team in inspecting and detecting the abnormalities on machine as leakages and worn out parts that may lead to breakdowns".

\section{Respondent Case $\mathrm{H}$ :}

“Implementing AM will improve our operators' skills and inculcate them with sense of ownership of the equipment. AM technique also relieves our maintenance team from a low value adding tasks so that they can focus on higher value adding maintenance tasks".

\section{4-6- Application of Tools, Technique and Technology}

Literature highlighted that the utilization of tools, techniques and technology is a must since it would ensure the effectiveness and sustainability of the MM program [51, 52]. From the case studies, it was observed that there were several efforts existed towards integrating the MM program with relevant tools, techniques and technology. For instance, 
the application of FMEA would enhance the analysis of equipment part in the MM activities (Case D and H). The application of predictive maintenance tools would facilitate the company in analyzing the maintenance data for equipment (Case D, E and H). According the respondent from Case B and C, recently, their respective companies have reviewed and updated the requirement for maintenance advanced tools. However, it will be subjected to financial allocation by the company. The effective MM requires the use and control of large amounts of data such as inventory of equipment spare parts and maintenance records on every single piece of equipment in the plant. Such data is best accomplished by computers. However, the findings from case studies show that the SMEs in the case studies were still using the conventional method (Case A to case H). However, many respondents from the case studies agreed the used of paperless system and CMMS would enable them track down and well manage the inventory of equipment parts and maintenance data (Case D, E and H).

\section{Respondent Case D:}

"We have hundreds of plant asset. Managing those assets is complex and time consuming. Is is great if our company can afford to purchase the CMMS, so that it can improve the efficiency of our tasks".

\section{Respondent Case H:}

"I would admit that our current data management practice is poor. The records of which equipment break down are recorded in manual maintenance log book and certain case it was gone in the technician's memory. We know that with CMMS, such data and record remains with the secured system, so when those technicians eventually left the company, their extensive and essential data and record doesn't leave with them".

\section{4-7- Maintenance Training}

An adequate and effective training program would beneficial in detecting the abnormalities of the equipment condition at the early stage $[53,54]$. Such report from literature, have triggered the researcher to observe on how SMEs manages the training and education related to MM program. When asked how MM training and education conducted in the company, a $60 \%$ of respondent (Case A, B, C and F) agreed that their respective companies have a little or no specific training for maintenance staff. According to respondent from Case C, any new maintenance staff will learn informally from their senior staff. That maintenance staffs only have the opportunity for formal training during commissioning of new machine, i.e. training from machine manufacturer.

\section{Respondent Case C:}

"Actually our company do not possess a formal training to train our maintenance staff. In fact, I would say that our company do not afford to offer such privilege. Any new maintenance staff, same goes to me, learnt informally. We learnt from our senior staff and learning by doing, by experience".

Respondent from Case A and F never support the idea of bringing out maintenance staff for external training due to huge investment need. Such practices in Case A, B, C and F contrast with the other companies (Case D, E and H). In which, in terms of training, there is a systematic progression plan in place for upgrading the technicians in the maintenance department. Companies D, E and $\mathrm{H}$ have encouraged their maintenance staff to gain a relevant competency training externally. Certain technicians are sent to a local college for training in the basic skills of mechanical and electrical engineering. However, there were a few restrictions and criteria that have to be fulfilled by applicant, for e.g., number of working experience, yearly performance rate and the relevancy of the course to the applicant job. Those selected to attend the external course will be subjected a binding agreement with company. Respondent from Case D and $\mathrm{H}$ claimed that the use of competent and experienced external trainers and consultants significantly contributed to their MM success. The competency of maintenance staff is having a close relationship with quality of repair work. The repetition of equipment problem happened in most of the companies, however, the frequency of repetition is varying. Respondent from Case A, B, C and F agreed that they having a high repetition of machine problem due to incompetent of maintenance staff.

\section{Respondent Case $\mathrm{H}$ :}

"Frankly speaking, I would say that the use of experienced and competent consultant really help us to manage the issue related to TPM. Even though the cost is expensive, such practice is rewarding”.

\section{Respondent Case B:}

"Most of repetitive equipment problems are a direct result of skill deficiencies. It really affected, cost a company a thousand of dollars per case".

\section{4-8- Record on Maintenance Data}

Obviously, many SMEs know little about the important of recording the equipment losses in their appropriate categories (Case A, B, C, F and G). It really alarming, that those companies do not record any specific records on overall equipment 
effectiveness (OEE) values: equipment operation (availability) rate; performance (efficiency) rate, and; quality rate. This is despite the highlighted from a literature that OEE is the metric that has been accepted in the manufacturing industry [55]. Respondent from Case F admitted that they never calculated the OEE values. This is contrast with the companies who introduced TPM in practice (Case D, E and H). In which they did some calculations and reported on OEE performance.

\section{4-9- Monitoring and Assessment}

Monitoring and assessment on MM development will allow the management team to review on the achievements and further improve any hitches in the process [56]. It was observed that MM program in the company was monitored and evaluated based on the three segments of monitoring and follow-up activity: daily, weekly and monthly (Case A case $\mathrm{H}$ ). As discussed earlier, companies D, E and $\mathrm{H}$ are vendor to company $\mathrm{X}$ and are implementing TPM on the workstation that produces Company X's items. It has indirectly established a good monitoring and evaluation system in companies D, E and $\mathrm{H}$. The daily segment is performed by operators and closely monitored by respective line leaders and supervisors. On the other hand, the weekly segment focuses on reviewing TPM performance at operational level. The TPM steering committee meeting is a monthly monitoring which is under the responsibility of management team. It is also part of preparation prior to audit by company X. Company $\mathrm{X}$ has conducted a periodic visit to its vendors (Case $\mathrm{D}, \mathrm{E}$ and $\mathrm{H}$ ) in order to monitor and evaluate the progress of TPM implementation.

\section{Respondent Case D:}

"We have got no option since 70 percent of our product goes to company X. We have set up our internal monitoring and evaluation to ensure that our product meet the specification".

\section{Respondent Case E:}

"Company X really stringent in monitoring and evaluating the progress TPM implementation in our company. The gemba (onsite audit) will be held in every three months".

\section{Respondent Case $\mathrm{H}$ :}

"The auditors from company X monitor and evaluate the TPM performance in our place. Vendor will be notified any shortcomings found during the audit. Those vendors failed the audit have to commit to take an immediate action on the shortcomings. Company $X$ is really concern on TPM, the results of the audits will be displayed on the vendor performance board in company $X^{\prime \prime}$.

\section{5- Key Criteria for Best Practice in Maintenance Management}

The cases reported in this paper focus on the case studies on eight (8) SMEs located in three (3) different areas, namely southern, central and eastern region of peninsular Malaysia. The companies involved were kept anonymous for ethical reasons. The findings from the case studies were synthesized and further analyzed using the "house of quality" (HOQ) techniques [57]. The objective is to find the most significance CSFs in managing the MM activity.

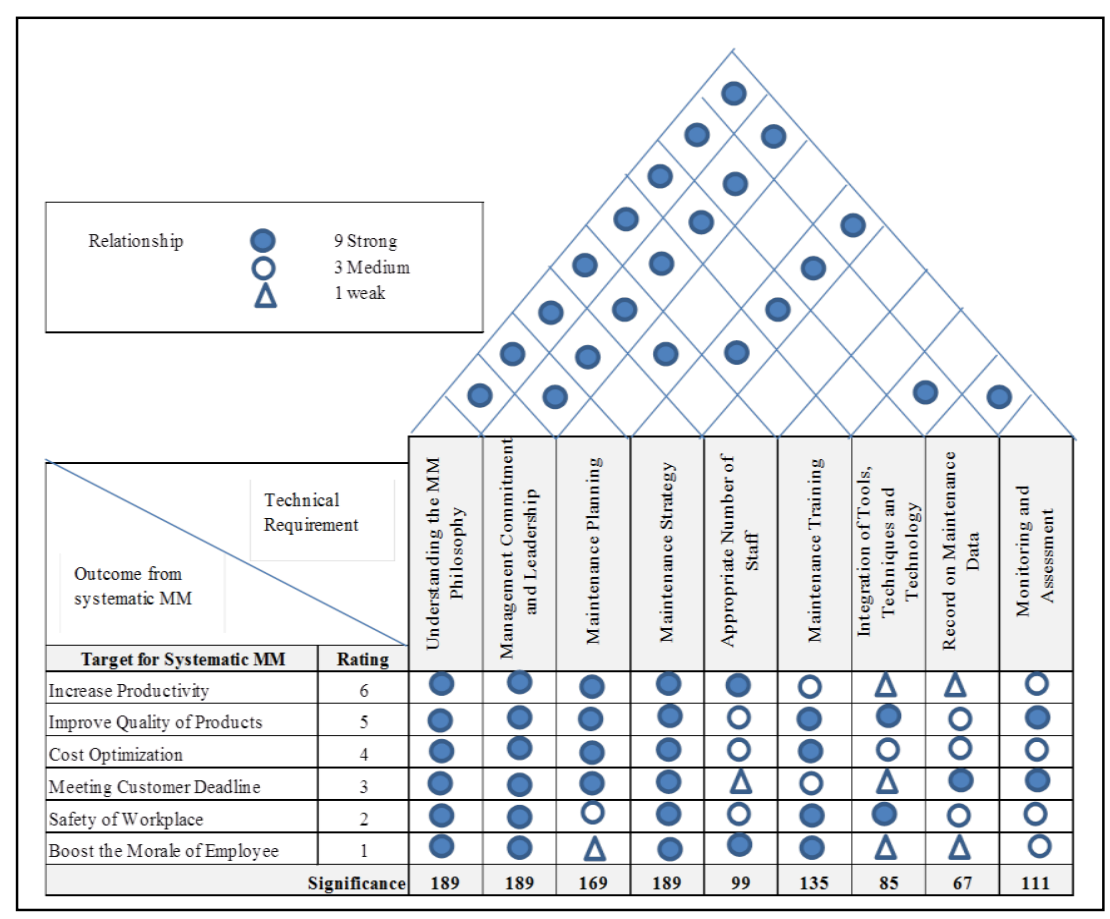

Figure 3. MM Framework II as Proposed by the researcher, adapted from [57, 58]. 
In actual practice of HOQ, it is a transition from simple cause-and-effect structure to a more rigid "house" structure. In this research, the conceptual framework or MM Framework I was designed using the cause-and-effect concept. Therefore, the researcher felt that it is practical to transform the cause-and-effect concept (MM Framework I) to the HOQ concept (MM Framework II). It is believed that this approach will clearly indicate the transition of a simpler framework (MM Framework I) to a more rigid framework (MM Framework II). Figure 3 shows the outline of MM Framework II, in which all CSFs constructs that is needed to be emphasized throughout the MM implementation program have been integrated. It is believed that this approach has made the MM Framework II as lean framework (simple yet self-explanatory) to convey the conceptual idea of MM implementation program to the management and technical people within SMEs.

\section{5-1- The Key CSFs from the Case Studies}

Figure 3 indicates three (3) main CSFs that are most significant to MM implementation program, namely: (1) Understanding the MM philosophy, (2) Management commitment and leadership, and (3) Maintenance strategy. Every employee should really understand and grasped the philosophy contained in the MM approach [29, 59]. It is a fundamental factor which must be established prior to start the MM implementation program. The MM policy must be established and should be incorporated with the existing company's policy. MM should be recognized as one of vital constituent of manufacturing management $[35,60]$. The top management should really recognize the benefits and outcomes from MM program from business survival and technical perspective. The top management should have confidence in the MM approach as proven technical strategy to optimize the company's assets (i.e. equipment) towards survival in the business. On the other perspective, the employee should confidence with the philosophy of MM as a proven program to protect their job in a long term. The optimistic outcome of MM such as: enhancing productivity, boosting superior product quality, optimizing operation cost, improving the delivery of products to customers, indoctrinating the morale of employees as well as creating a safe working environment should be highlighted to the employee.

\section{6- Conclusion}

This study reveals the actual emphasized of the case study companies towards the CSFs constructs of MM program. Several deficiencies were identified particularly on the issue related to management commitment and leadership, maintenance planning and maintenance strategy. The researchers have summarized the findings and outcomes of the study into one integrated framework, denoted as MM Framework II (as shown in Figure 3). The MM Framework II serves as a major contribution of this study. The framework integrates all of the CSFs in MM implementation program. It is believed that the framework developed would be able to be used by SME company's management as a guideline towards a systematic MM implementation program. Eequipment efficiency should include product quality index as well rather than focusing on the equipment availability alone. Thus, the MM program should be integrated as an important constituent of in QI initiatives. Ineffective MM will have significant impact on company's profitability. As consequences, a huge amount on maintenance of inefficient production equipment would increase the company operational costs. MM program is considered as "the last frontier" for manufacturing facilities. Effective integration MM program and QI initiatives is one of the vital requirements towards achieving world-class manufacturing. In this sense, reliable equipment is considered as the main elements towards performance as well as profitability of the organization.

\section{7- Declarations}

\section{7-1-Author Contributions}

A.B., M.F.M.A., N.A., F.J., M.A.I., A.N.A., and I.H.Z. contributed to the design and implementation of the research, to the analysis of the results and to the writing of the manuscript. All authors have read and agreed to the published version of the manuscript.

\section{7-2-Data Availability Statement}

The data presented in this study are available on request from the corresponding author.

\section{7-3-Ethical Approval}

Participants gave their written consent to use their anonymous data for statistical purposes. All of them were over 18 years old and voluntarily collaborated without receiving any financial compensation.

\section{7-4- Funding and Acknowledgements}

The authors would like to thank Universiti Kuala Lumpur (UniKL) for supporting this research under the Short Term Research Grant (STRG). 


\section{7-5- Conflicts of Interest}

The authors declare that there is no conflict of interests regarding the publication of this manuscript. In addition, the ethical issues, including plagiarism, informed consent, misconduct, data fabrication and/or falsification, double publication and/or submission, and redundancies have been completely observed by the authors.

\section{8- References}

[1] Bakri, A. \& Zakaria, I. H. "Uplifting the Function of Maintenance Management towards Sustainable Performance of Laboratory and Workshop in TVET Institutions." The Journal of Social Sciences Research no. 6 (December 26, 2018): 153-160. doi:10.32861/jssr.spi6.153.160.

[2] Rolfsen, Monica, and Camilla Langeland. "Successful Maintenance Practice through Team Autonomy.” Edited by Abigail Marks. Employee Relations 34, no. 3 (April 21, 2012): 306-321. doi:10.1108/01425451211217725.

[3] Phogat, Sandeep, and Anil Kumar Gupta. "Expected Maintenance Waste Reduction Benefits after Implementation of Just in Time (JIT) Philosophy in Maintenance (a Statistical Analysis).” Journal of Quality in Maintenance Engineering 25, no. 1 (March 11, 2019): 25-40. doi:10.1108/jqme-03-2017-0020.

[4] AL Mannai, B., S.M.A. Suliman, and Y. AL Alawai. “An Investigation Into The Effects Of The Application Of TQM, TPM, And Jit On Performance Of Industry In Bahrain.” International Journal of Industrial Engineering Research and Development 8, no. 1 (February 28, 2017). doi:10.34218/ijierd.8.1.2017.002.

[5] Bahria, Nadia, Anis Chelbi, Imen Harbaoui Dridi, and Hanen Bouchriha. "Maintenance and Quality Control Integrated Strategy for Manufacturing Systems.” European J. of Industrial Engineering 12, no. 3 (2018): 307. doi:10.1504/ejie.2018.092006.

[6] M. Gaikwad, Lokpriya, and Vivek K. Sunnapwar. "Integrated Lean-Green-Six Sigma Practices to Improve the Performance of the Manufacturing Industry." Concepts, Applications and Emerging Opportunities in Industrial Engineering (January 7, 2021). doi:10.5772/intechopen.93276.

[7] Nascimento, Daniel Luiz de Mattos, Osvaldo Luiz Goncalvez Quelhas, Rodrigo Goyannes Gusmão Caiado, Guilherme Luz Tortorella, Jose Arturo Garza-Reyes, and Luis Rocha-Lona. "A Lean Six Sigma Framework for Continuous and Incremental Improvement in the Oil and Gas Sector.” International Journal of Lean Six Sigma 11, no. 3 (September 16, 2019): 577-595. doi:10.1108/ijlss-02-2019-0011.

[8] Garza-Reyes, Jose Arturo, Mingyang Yu, Vikas Kumar, and Arvind Upadhyay. "Total Quality Environmental Management: Adoption Status in the Chinese Manufacturing Sector.” The TQM Journal 30, no. 1 (January 8, 2018): 2-19. doi:10.1108/tqm05-2017-0052.

[9] Bakri, Adnan Hj., Abdul Rahman Abdul Rahim, and Noordin Mohd Yusof. "Total Productive Maintenance: Competing or Complementary to Other Initiatives?" Applied Mechanics and Materials 315 (April 2013): $472-476$. doi:10.4028/www.scientific.net/amm.315.472.

[10] Farahani, Ameneh, and Hamid Tohidi. "Integrated Optimization of Quality and Maintenance: A Literature Review." Computers \& Industrial Engineering 151 (January 2021): 106924. doi:10.1016/j.cie.2020.106924.

[11] Modranský, Róbert, Silvia Jakabová, and Albert Oláh. "Innovation Management and Barriers - Creating Space for Innovation and Organizational Change.” Emerging Science Journal 4, no. 5 (October 1, 2020): 345-364. doi:10.28991/esj-2020-01236.

[12] Abbas, Jawad. "Impact of Total Quality Management on Corporate Sustainability through the Mediating Effect of Knowledge Management.” Journal of Cleaner Production 244 (January 2020): 118806. doi:10.1016/j.jclepro.2019.118806.

[13] Mohammad Mosadeghrad, Ali. "Obstacles to TQM Success in Health Care Systems." International Journal of Health Care Quality Assurance 26, no. 2 (February 2013): 147-173. doi:10.1108/09526861311297352.

[14] Zhang, Xugang, Yuanjie Tang, Hua Zhang, Zhigang Jiang, and Wei Cai. "Remanufacturability Evaluation of End-of-Life Products Considering Technology, Economy and Environment: A Review.” Science of The Total Environment 764 (April 2021): 142922. doi:10.1016/j.scitotenv.2020.142922.

[15] Phogat, Sandeep, and Anil Kumar Gupta. "Development of Framework for Just-in-Time Implementation in Maintenance." Journal of Quality in Maintenance Engineering 24, no. 4 (October 8, 2018): 488-510. doi:10.1108/jqme-08-2017-0052.

[16] Phan, Anh Chi, Ha Thu Nguyen, Hao Anh Nguyen, and Yoshiki Matsui. "Effect of Total Quality Management Practices and JIT Production Practices on Flexibility Performance: Empirical Evidence from International Manufacturing Plants." Sustainability 11, no. 11 (May 31, 2019): 3093. doi:10.3390/su11113093.

[17] Rivera-Gómez, Héctor, Oscar Montaño-Arango, José Corona-Armenta, Jaime Garnica-González, Antonio Ortega-Reyes, and Gustavo Anaya-Fuentes. “JIT Production Strategy and Maintenance for Quality Deteriorating Systems.” Applied Sciences 9, no. 6 (March 20, 2019): 1180. doi:10.3390/app9061180.

[18] Bakri, Hj. Adnan, Abdul Rahman Abdul Rahim, and Noordin bin Mohd Yusof. "Maintenance Management: Rationale of TPM as the Research Focus.” Applied Mechanics and Materials 670-671 (October 2014): 1575-1582. doi:10.4028/www.scientific.net /amm.670-671.1575. 
[19] Sánchez-Barroso, Gonzalo, and Justo G. Sanz-Calcedo. “Application of Predictive Maintenance in Hospital Heating, Ventilation and Air Conditioning Facilities.” Emerging Science Journal 3, no. 5 (October 1, 2019): 337-343. doi:10.28991/esj-2019-01196.

[20] Naghibi, Hosseinali, Hassan Farsijani, Masoud Kasaei, and Mustafa Zandieh. "Explanation of effective components in the structure of world class manufacturing in the automotive industry." Modern Research in Decision Making 1, no. 4 (2017): 167186.

[21] Jasiulewicz-Kaczmarek, Malgorzata, Anna Saniuk, and Tadeusz Nowicki. "The Maintenance Management in the MacroErgonomics Context.” Advances in Social \& Occupational Ergonomics (July 27, 2016): 35-46. doi:10.1007/978-3-319-41688$5 \_4$.

[22] Sahoo, Saumyaranjan, and Sudhir Yadav. “Total Quality Management in Indian Manufacturing SMEs.” Procedia Manufacturing 21 (2018): 541-548. doi:10.1016/j.promfg.2018.02.155.

[23] Bakri, Adnan Hj., Abdul Rahman Abdul Rahim, Noordin Mohd. Yusof, and Ramli Ahmad. "Boosting Lean Production via TPM.” Procedia - Social and Behavioral Sciences 65 (December 2012): 485-491. doi:10.1016/j.sbspro.2012.11.153.

[24] Sharma, Vivek, Sandeep Grover, and S.K. Sharma. "Applicability of Quality Tools and Techniques in Manufacturing and Service Organisations: a Comprehensive Survey.” International Journal of Six Sigma and Competitive Advantage 12, no. 1 (2020): 37. doi:10.1504/ijssca.2020.107465.

[25] Ishikawa, Kaoru. Introduction to quality control. Productivity Press, 1990.

[26] Bakri, Adnan Bin. "Total Productive Maintenance Framework." Doctoral Dissertation, Universiti Teknologi Malaysia, 2015.

[27] Davey, Melinda E., and Jonathan A. Morell. "Method for Using Rubric Ratings on Fishbone Diagrams to Compare Case Studies." Journal of MultiDisciplinary Evaluation 16, no. 34 (2020): 56-64.

[28] Bakri, Hj Adnan, Abdul Rahman Abdul Rahim, Mohd Yusof Noordin, Widya Kartini Mohd Razali, Mohd.Tohid Mohd ZulWaqar, and Ismail Shaiful Anwar. "A Review on the Total Productive Maintenance (TPM) Conceptual Framework." Applied Mechanics and Materials 660 (October 2014): 1043-1051. doi:10.4028/www.scientific.net/amm.660.1043.

[29] Kaswan, Mahender Singh, and Rajeev Rathi. "Green Lean Six Sigma for Sustainable Development: Integration and Framework." Environmental Impact Assessment Review 83 (July 2020): 106396. doi:10.1016/j.eiar.2020.106396.

[30] Singh, Jagdeep, Harwinder Singh, and Vinayak Sharma. "Success of TPM Concept in a Manufacturing Unit - a Case Study." International Journal of Productivity and Performance Management 67, no. 3 (March 5, 2018): 536-549. doi:10.1108/ijppm-012017-0003.

[31] Han, Yuzhen, and Yong Deng. “A Hybrid Intelligent Model for Assessment of Critical Success Factors in High-Risk Emergency System." Journal of Ambient Intelligence and Humanized Computing 9, no. 6 (June 2, 2018): 1933-1953. doi:10.1007/s12652018-0882-4.

[32] Leiber, Theodor, Bjørn Stensaker, and Lee Colin Harvey. "Bridging Theory and Practice of Impact Evaluation of Quality Management in Higher Education Institutions: a SWOT Analysis.” European Journal of Higher Education 8, no. 3 (May 31, 2018): 351-365. doi:10.1080/21568235.2018.1474782.

[33] Ayo-Imoru, R.M., and A.C. Cilliers. "A Survey of the State of Condition-Based Maintenance (CBM) in the Nuclear Power Industry.” Annals of Nuclear Energy 112 (February 2018): 177-188. doi:10.1016/j.anucene.2017.10.010.

[34] Karajagikar, Jayant S., and B. U. Sonawane. "Reliability-Centered Maintenance (RCM) Approach for a Process Industry: Case Study.” Optimization Methods in Engineering (June 6, 2020): 429-442. doi:10.1007/978-981-15-4550-4_26.

[35] Khalfallah, Meriem, and Lassaad Lakhal. "The Relationships between TQM, TPM, JIT and Agile Manufacturing: An Empirical Study in Industrial Companies.” The TQM Journal ahead-of-print, no. ahead-of-print (March 8, 2021). doi:10.1108/tqm-122020-0306.

[36] Rasay, Hassan, Mohammad Saber Fallahnezhad, and Yahia Zaremehrjerdi. "Integration of the decisions associated with maintenance management and process control for a series production system." Iranian Journal of Management Studies 11, no. 2 (2018): 379-405. doi:10.22059/IJMS.2018.246049.672912.

[37] Medenou, Daton, Latif A. Fagbemi, Roland C. Houessouvo, Thierry R. Jossou, Mêtowanou H. Ahouandjinou, Davide Piaggio, Chams-Deen A. Kinnouezan, et al. "Medical Devices in Sub-Saharan Africa: Optimal Assistance via a Computerized Maintenance Management System (CMMS) in Benin." Health and Technology 9, no. 3 (March 19, 2019): $219-232$. doi:10.1007/s12553-018-00283-3.

[38] Perez-Ramirez, Miguel, G. Arroyo-Figueroa, and A. Ayala. "The Use of a Virtual Reality Training System to Improve Technical Skill in the Maintenance of Live-Line Power Distribution Networks." Interactive Learning Environments (March 14, 2019): 118. doi:10.1080/10494820.2019.1587636.

[39] Bao, Zuohui, Yong Wang, Zuobin Yang, Chunfeng Zhu, and Cheng Jin. "Design on the Virtual Maintenance Training System of Some-Type Equipment Based on the Virtual Reality." Lecture Notes in Electrical Engineering (September 25, 2018): 479487. doi:10.1007/978-981-13-2481-9_56. 
[40] Cheah, Chew Keat, Joshua Prakash, and Kok Seng Ong. "An Integrated OEE Framework for Structured Productivity Improvement in a Semiconductor Manufacturing Facility.” International Journal of Productivity and Performance Management 69, no. 5 (February 25, 2020): 1081-1105. doi:10.1108/ijppm-04-2019-0176.

[41] Jradi, M., K. Arendt, F.C. Sangogboye, C.G. Mattera, E. Markoska, M.B. Kjærgaard, C.T. Veje, and B.N. Jørgensen. “ObepME: An Online Building Energy Performance Monitoring and Evaluation Tool to Reduce Energy Performance Gaps.” Energy and Buildings 166 (May 2018): 196-209. doi:10.1016/j.enbuild.2018.02.005.

[42] Rahadi, K B, A Setyanto, and D Rohmansyah. "Application of Theory of Constraints (TOC) in Power Generation to Increase Overhaul Maintenance Performance and to Strengthen Overhaul Management Process." IOP Conference Series: Materials Science and Engineering 1096, no. 1 (March 1, 2021): 012130. doi:10.1088/1757-899x/1096/1/012130.

[43] Yin, Robert K. Case study research and applications: Design and methods. Sage publications, 2017.

[44] Pascal, Vrignat, Aggab Toufik, Avila M., Duculty Florent, and Kratz Frédéric. "Improvement Indicators for Total Productive Maintenance Policy.” Control Engineering Practice 82 (January 2019): 86-96. doi:10.1016/j.conengprac.2018.09.019.

[45] Lovita, Erna, and Gatot Prabantoro. "Revealing Internal Control Practices in SME Capital Maintenance.” Proceedings of the 5th Annual International Conference on Accounting Research (AICAR 2018) (2019). doi:10.2991/aicar-18.2019.2.

[46] Foteinis, S., and T. Tsoutsos. "Strategies to Improve Sustainability and Offset the Initial High Capital Expenditure of Wave Energy Converters (WECs).” Renewable and Sustainable Energy Reviews 70 (2017): 775-785. doi:10.1016/j.rser.2016.11.258.

[47] Welte, Thomas Michael, Iver Bakken Sperstad, E. Espeland Halvorsen-Weare, Øyvind Netland, Lars Magne Nonås, and Magnus Stålhane. "Operation and maintenance modelling." Offshore Wind energy technology 269 (2018).

[48] Paprocka, Iwona. "The Model of Maintenance Planning and Production Scheduling for Maximising Robustness." International Journal of Production Research 57, no. 14 (July 5, 2018): 4480-4501. doi:10.1080/00207543.2018.1492752.

[49] Zhu, Sha, Willem van Jaarsveld, and Rommert Dekker. "Spare Parts Inventory Control Based on Maintenance Planning." Reliability Engineering \& System Safety 193 (January 2020): 106600. doi:10.1016/j.ress.2019.106600..

[50] Basri, Ernnie Illyani, Izatul Hamimi Abdul Razak, Hasnida Ab-Samat, and Shahrul Kamaruddin. "Preventive Maintenance (PM) Planning: a Review." Journal of Quality in Maintenance Engineering 23, no. 2 (May 8, 2017): 114-143. doi:10.1108/jqme-042016-0014.

[51] Ismail, Zul-Atfi. “ICT-Based System for Malaysian Residential Maintenance Projects - Literature Review.” Journal of Facilities Management 16, no. 3 (July 2, 2018): 354-371. doi:10.1108/jfm-06-2016-0026.

[52] Saha, Rajesh, Abdullahil Azeem, Kazi Wahadul Hasan, Syed Mithun Ali, and Sanjoy Kumar Paul. "Integrated Economic Design of Quality Control and Maintenance Management: Implications for Managing Manufacturing Process.” International Journal of System Assurance Engineering and Management 12, no. 2 (January 23, 2021): 263-280. doi:10.1007/s13198-021-01053-7..

[53] Jasiulewicz-Kaczmarek, Małgorzata, and Patryk Żywica. “The Concept of Maintenance Sustainability Performance Assessment by Integrating Balanced Scorecard with Non-Additive Fuzzy Integral.” Eksploatacja i Niezawodnosc - Maintenance and Reliability 20, no. 4 (September 18, 2018): 650-661. doi:10.17531/ein.2018.4.16.

[54] Palmarini, Riccardo, John Ahmet Erkoyuncu, and Rajkumar Roy. “An Innovative Process to Select Augmented Reality (AR) Technology for Maintenance.” Procedia CIRP 59 (2017): 23-28. doi:10.1016/j.procir.2016.10.001.

[55] Zhou, Junhong, Yu Wang, and Yong Quan Chua. "Machine OEE Monitoring and Analysis for a Complex Manufacturing Environment." 2020 15th IEEE Conference on Industrial Electronics and Applications (ICIEA) (November 9, 2020). doi:10.1109/iciea48937.2020.9248351.

[56] Mahfoud, Hassana, Abdellah El Barkany, and Ahmed El Biyaali. "Medical Maintenance Performance Monitoring: a Roadmap to Efficient Improvement." International Journal of Productivity and Quality Management 22, no. 1 (2017): 117. doi:10.1504/ijpqm.2017.085850.

[57] Adinyira, E., T. E. Kwofie, and F. Quarcoo. "Stakeholder Requirements for Building Energy Efficiency in Mass Housing Delivery: The House of Quality Approach.” Environment, Development and Sustainability 20, no. 3 (March 6, 2017): 11151131. doi:10.1007/s10668-017-9930-z.

[58] Ramírez, Yendery, Luis A. Cisternas, and Andrzej Kraslawski. "Application of House of Quality in Assessment of Seawater Pretreatment Technologies.” Journal of Cleaner Production 148 (April 2017): 223-232. doi:10.1016/j.jclepro.2017.01.163.

[59] Hari Prasad, B., and Mahesh Bhardwaj. “An Integrated Maintenance Management: A Practical Approach.” Recent Advances in Mechanical Engineering (December 29, 2020): 141-147. doi:10.1007/978-981-15-8704-7_17..

[60] Ness, David A., and Ke Xing. “Toward a Resource-Efficient Built Environment: A Literature Review and Conceptual Model.” Journal of Industrial Ecology 21, no. 3 (April 21, 2017): 572-592. doi:10.1111/jiec.12586. 